\title{
Harcourt - Le château : châtelet d'entrée
}

Damien Thomire

URL : http://journals.openedition.org/adlfi/16585

ISSN : 2114-0502

Éditeur

Ministère de la culture

Référence électronique

Damien Thomire, « Harcourt - Le château : châtelet d'entrée », ADLFI. Archéologie de la France -

Informations [En ligne], Haute-Normandie, mis en ligne le 18 février 2016, consulté le 19 avril 2019.

URL : http://journals.openedition.org/adlfi/16585

Ce document a été généré automatiquement le 19 avril 2019

(c) Ministère de la Culture et de la Communication, CNRS 


\title{
Harcourt - Le château : châtelet d'entrée
}

\author{
Damien Thomire
}

Code INSEE commune : 27311

Lien Atlas (MCC) :

http://atlas.patrimoines.culture.fr/atlas/trunk/index.php?

ap_theme=DOM_2.01.02\&ap_bbox=0.727;49.146;0.820;49.186

1 Le châtelet du château d'Harcourt a fait l'objet d'une étude englobant les maçonneries et la charpente dans le cadre d'un master recherche en archéologie à l'université de Rouen, sous la direction d'Élisabeth Lorans, Anne-Marie Flambard-Héricher, Frédéric Épaud et Emmanuel Pous. Cette étude a révélé quatre phases de construction et de modification de l'édifice entre le XIII et le début du XviII $\mathrm{s}$.

2 Le château est construit sur le bord sud-est d'un vallon sec de la plaine du Neubourg, délimitée par les vallées de la Risle et de l'Iton. Il domine la rive droite de la Risle, située à $5 \mathrm{~km}$ à l'ouest.

3 Au même titre que le château de Sébécourt, il s'intègre dans un réseau de fortifications qui bordent la vallée. L'ensemble de la fortification se présente sous la forme d'une motte arasée, sur laquelle se trouve un château polygonal entouré d'un fossé intérieur précédé par une basse-cour. Celle-ci est ceinturée par une enceinte à cinq tours flanquantes semicirculaires à archères avec deux portes d'entrée, la Porte Piquet en ruine au nord et le châtelet au sud. Ce dernier correspond à la porte d'entrée de la basse-cour, face à la paroisse d'Harcourt. La Porte Piquet est tournée vers le vallon sec et défendue par une barbacane. 


\section{Phase 1 : construction des tours ( $\mathrm{XIII}$ s.)}

4 D'après le relevé des maçonneries il semble que le châtelet ait été construit à l'origine comme une porte de l'enceinte avec deux tours circulaires, probablement avec un pont au-dessus du fossé extérieur. Cette porte était défendue par des archères, certaines sont encore visibles à ce jour. Nous estimons cette première phase aux alentours de la fin du $\mathrm{XIII}^{\mathrm{e}} \mathrm{s}$.

\section{Phase 2 : construction du bâtiment rectangulaire (fin XIII ${ }^{\mathrm{e}}$-début XIV $\mathrm{s}$.)}

Dans une deuxième phase de construction un bâtiment rectangulaire est construit dans la basse-cour pour se greffer aux tours. C'est alors que l'on peut parler de châtelet. Le plan au sol de ce bâtiment est quasiment le même que celui que nous avons aujourd'hui avec un niveau de circulation environ $1 \mathrm{~m}$ au-dessus du niveau actuel. L'ajout du bâtiment rectangulaire montre une volonté d'améliorer la défense de l'entrée. Le bâtiment est constitué de deux salles dans le prolongement des tours et d'un couloir de $14 \mathrm{~m}$ avec une portée de 2,20 m entre ces deux salles. Le couloir était défendu par au moins deux archères. Elles sont visibles dans la salle ouest du rez-de-chaussée. Il était également équipé de deux herses et d'un assommoir, créant ainsi un système de sas. L'ensemble est clairement visible sur le relevé du plafond du couloir. L'absence de chaînage entre le bâtiment rectangulaire et les tours permet de déterminer qu'il y a bien deux phases distinctes.

6 Au premier étage se trouve une grande salle de $73,50 \mathrm{~m}^{2}$ qui couvre toute la largeur du bâtiment. L'accès au premier étage se faisait probablement grâce à un escalier droit en pierre calcaire le long du mur occidental de la salle est. Il ne reste à ce jour que l'empreinte de cet escalier dans le mur.

7 L'étude de la charpente, constituée en partie de bois de réemplois, a permis de restituer la structure d'origine, correspondant à cette deuxième phase de construction. La charpente actuelle, du début du XVIII ${ }^{e}$ s., est à fermes et pannes, et comprend trois fermes qui occupent l'espace de circulation du premier étage. Ces fermes sont composées d'un entrait à seulement $0,60 \mathrm{~m}$ du sol, d'un poinçon de fond, d'un arbalétrier portant la partie nord de la couverture, d'un second au sud et de deux contrefiches entre l'arbalétrier nord et le poinçon. La forme asymétrique des fermes vient du fait que les deux murs opposés ne sont pas de même hauteur. Le mur nord a été détruit en phase 4 et abaissé à $0,70 \mathrm{~m}$ du sol de l'étage.

8 D'après les réemplois, la charpente d'origine de cette salle haute était à chevronsformant-fermes, voûtée et lambrissée, et composée d'au moins 3 fermes principales et de 21 fermes secondaires.

9 Cette salle haute, pourvue d'une grande cheminée et d'une charpente voûtée, pouvait correspondre à une salle de justice. 


\section{Phase 3 : réaménagement intérieur $\left(x v^{e} s.\right)$}

10 la fonction du châtelet qui change. Si la phase 2 est clairement une amélioration de la défense de la porte, la suivante est caractérisée par un démantèlement des attributs défensifs principaux pour passer à un aménagement propice à l'accueil. Le niveau de circulation est abaissé d'environ $1 \mathrm{~m}$ au rez-de-chaussée. Les archères de la salle ouest sont obturées. Les murs sont recouverts d'un enduit à la chaux blanche, peint avec un faux joint pourpre. L'accès au premier étage évolue: l'escalier droit est détruit et remplacé par un escalier à vis dans la maçonnerie du mur gouttereau nord, accessible depuis la salle est. Le seuil de cet escalier est encore visible au premier étage, dans un renfoncement de 0,20 $\mathrm{m}$ sur $1,30 \mathrm{~m}$ au nord-est.

$11 \mathrm{Au}$ premier étage, les murs sont également peints. Il y a encore quelques traces de faux joints pourpres ainsi que de la peinture jaune. En ce qui concerne le couloir, sa portée a été augmentée, les dispositifs de fermeture et l'assommoir ont été supprimés et comblés. Pour réaliser cet élargissement, les maçonneries des tours ont été démaigries. La portée du couloir est passée de 2,80 à $3,10 \mathrm{~m}$.

\section{Phase 4 (fin XVII ${ }^{\mathrm{e}}$-début XVIII $\mathrm{s}$.)}

Dans cette quatrième phase, nous avons une vaste transformation de l'édifice, commandée par Françoise de Brancas. Nous pensons que le mur gouttereau nord avec son escalier a été détruit ou s'est effondré, emportant la charpente voûtée de la salle haute. Le mur a en tout cas été reconstruit, seulement jusqu'au sol de l'étage. Le charpentier s'est donc adapté à cette différence de hauteur avec une toiture asymétrique à deux versants. Pour remplacer l'escalier à vis, un escalier droit en bois est construit dans la salle ouest contre le mur pignon occidental, permettant l'accès au premier étage. La mise en place de cet escalier a nécessité le percement d'une tranchée dans le plancher au pied de la cheminée du premier étage, impliquant l'obsolescence de cette dernière.

Le châtelet du château d'Harcourt est un bâtiment difficile à appréhender tant il y a de traces de modifications. L'utilisation du silex et du mortier comme matériaux dominants rend l'interprétation des maçonneries particulièrement hasardeuse. Ceci dit, même s'il reste quelques parts d'ombre en raison du manque de sources écrites, notamment sur les causes de la démolition du mur gouttereau nord, nous pensons globalement avoir mis en évidence les grandes phases de construction et de modification du châtelet au cours des siècles. Par ailleurs, les fouilles menées récemment sur la porte Piquet permettront de parfaire la connaissance de l'évolution des dispositifs d'accès au château d'Harcourt. 


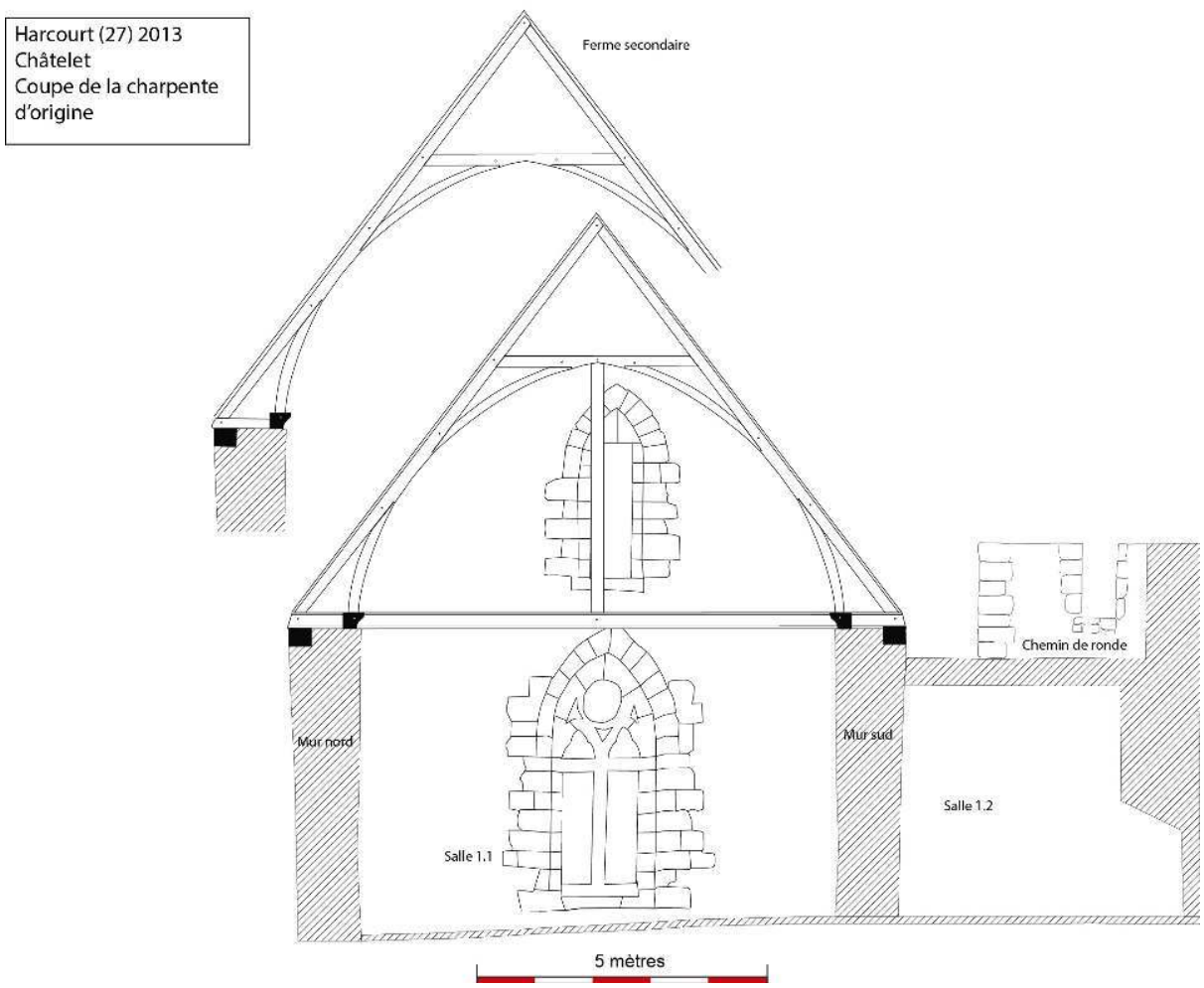

Fig. 01

Coupe de la charpente d'origine

DAO : D. Thomire

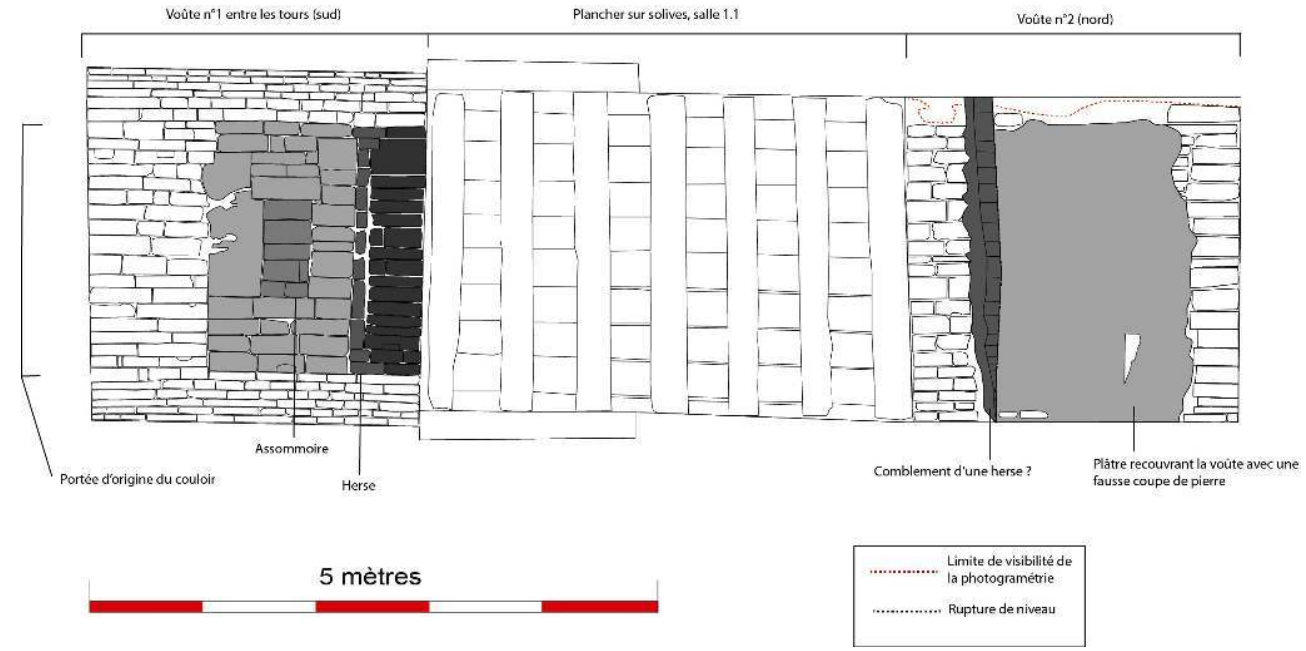

Fig. 02

Plafond du couloir

DAO : D. Thomire 
INDEX

Index géographique : Normandie, Eure (27), Harcourt

operation Autre étude (AET)

Mots-clés : château, fortification, mur d'enceinte, porte, châtelet, tour Index chronologique : Moyen Âge

\section{AUTEURS}

\section{DAMIEN THOMIRE}

Université de Rouen 